\title{
Albanon
}

Revistë kulturore

\section{Albanologu Kristian Gyt}

\author{
Remzi Përnaska, Tomorr Plangarica
}

... dhe diku, në një cep të tavolinës së punës së albanologut, disa fletë të përkthimit në frëngjisht të pjesës shtesë të Shkëlqimi dhe rënia e shokut Zylo të sapodërguar në shtëpinë botuese franceze duket se mezi çpresin të renditen në dosjen e romanit të plotësuar tashmë edhe në frëngjisht; heshturazi, ato fletë të shkruara dëshmojnë përmbushjen e premtimit nga ana e albanologut; pranë tyre një fletore, me një medaljon me portretin e Dritëroit në kopertinë, dërguar në këtë fundnëntor nga vajza e Dritëroit, si shenjë mirënjohjeje e përmallimi ndaj albanologut; ... dhe pranë saj, edhe një gotë e mbushur përgjysmë me raki mani të Boboshticës duket se pret të trokitet sërish mes dy miqve, si dikur kur diskutonin për histori e letërsi, zakone e tradita të atij populli që Dritëroi i përkiste dhe i këndonte, e ndaj të cilave albanologu mbeti $i$ tërhequr gjithë jetën e u mundua t’ia dhurojë e bëjë të ditur edhe francezëve në gjuhën e tyre; e në cepin tjetër të tavolinës së punës, $i$ hapur në një faqe nga fundi, Kanuni i Lekë Dukagjinit, të cilin albanologu e solli në frëngjisht, me durimin e këmbënguljen e atij që imtësitë $i$ kushtojnë më shumë se e tëra, një punë pothuaj pesëmbëdhjetë vjeçare. Diçka i ka ardhur në mendje në këto ditë të ligështimit të skajshëm trupor dhe ka dashur ta verifikojë; ndoshta ende një imtësi për të drejtën zakonore shqiptare për të cilën ka vite që studion e shkruan.

Dhe aty përballë, pranë dëshmive të shumta të vlerësimit të punës së tij nga shteti francez, pranë titujve e dekoratave Kalorës i Urdhërit Kombëtar të Legjionit të Nderit (Chevalier de l'Ordre national de la Légion d'honneur), Kalorës i Urdhërit Kombëtar të Meritës (Chevalier de l'Ordre national du Mérite), Oficer i Arteve dhe Letrave (Officier des Arts et des Lettres), ja dhe dëshmitë si Anëtar i jashtëm i Akademisë së Shkencave dhe Arteve të Kosovës, Profesor i jashtëzakonshëm i Universitetit «Aleksandër Xhuvani» të Elbasanit, Doktor Honoris Causa i Universitetit të Tiranës, Qytetar nderi i qytetit të Elbasanit. 
Eshtë aty në studion e tij mes mijëra librash, madje të tillë edhe qindravjeçarë; diku në rafte, mes librave tejet të vjetër në formë dorëshkrimesh, ka edhe librin e parë të Gutenbergut; por në ditët e ligshtisë së madhe trupore, kënaqësinë e gjen te pasioni e dashuria për kulturën e popullit të vogël shqiptar; popull i vogël, por që diti të ketë monumente të mëdha; ndaj edhe në ato ditë të fundme lexon etshëm e shkruan me dorën e lodhur për atë histori, sikur kërkon të bartë sa më shumë informacion me vete në udhëtimin astral të cilin e pret gjakftohtë dhe me shpërfillje, për të qenë atje, "përtej” përgjithnjë me këtë dashuri të jetës.

Dhe duket se $i$ tillë udhëtoi shpirti i tij më 26 nëntor 2018, kur albanologu Kristian Gyt ndërroi jetë.

Është e natyrshme që kontributet e dijetarëve të huaj (gjuhëtarë, historianë, etnologë, kulturologë etj.) në fushën e albanologjisë të jenë përvijuar si kontribute që vijnë në këtë fushë krahas prurjeve shkencore që ata sjellin në fushat e tjera parësore të interesimeve të tyre shkencore që lidhen jo vetëm me Shqipërinë, historinë e saj dhe gjuhën shqipe, por me kontekstet shkencore ku ata punojnë ose me gjuhët e ndryshme të Europës e Ballkanit, ose edhe më tej, me gjuhë të ndryshme indoeuropiane e më gjerë. Është e natyrshme po ashtu që interesimet e para për gjuhën, kulturën dhe historinë e popullit shqiptar të kenë lindur, si fillesë, nga kureshtja e sqima e tyre shkencore së cilës shqipja i jepte argumente jo të pakta për krahasime dhe përqasje, dhe historia e kultura e popullit shqiptar modele parake të konservimit të vlerave dhe zakoneve, etj. Edhe pse i krijuar me këtë zanafillë, kontributi i tyre mbetet i çmuar për albanologjinë dhe, në të shumtën e rasteve, edhe për çështjen shqiptare në rrjedhë të viteve dhe epokave, kur jo pak herë zëri i tyre ka qenë tejet i rëndësishëm në administratën e vendeve të tyre a në kancelaritë e ndryshme të vendeve europiane. Përvoja e përftuar prej këtyre kontributeve është e pranishme tashmë në bibliotekat europiane e më gjerë, e po ashtu, gjurmët e fjalës së tyre dallohen jo pak herë edhe në analet e politikës, historisë e diplomacisë europiane.

Në emrat më të njohur të kësaj trashëgimie, në suazën e kontributeve të studiuesve francezë për albanologjinë, spikatin emra të shquar si Lui Lysiën Bonoparti (Louis-Lucien Bonaparte), Ogyst Dozoni (Auguste Dozon), Lui Benlëvi (Louis Benloew), Lui Pod'horski (Louis Podhorszky), Mario Roku (Mario Roques), Gabriel Anceu (Gabriel Ancey), Robert d'Anzhëli (Robert d'Angely), Hanri Buasëni (Henri Boissin), Zhan-Lui Dysheja (Jean-Louis Duchet), Zhorzhë Dretasi (Georges Drettas), etj..Për një rastësi të lumtur, 


\section{Albanon}

\section{Revistë kulturore}

por jo vetëm për rastësi, këto janë figura të rëndësishme me prurje të konsiderueshme në kulturën dhe studimet europiane. Ndoshta zhvillimet historike dhe kulturologjike të shekullit XIX dhe gjysmës së parë të shekullit $\mathrm{XX}$, si dhe shkollat gjuhësore dhe historiografike të asaj periudhe, por edhe kahje të ndryshme shkollash gjuhësore më vonë e parakuptonin dhe e nxisnin këtë natyre komplekse dhe enciklopedike të studimit.

Si për vijimësi të asaj tradite, por të formësuar në kushte aspak të njëjta, kontributi i K. Gytit, në gjysmën e dytë të shekullit XX, do të ketë pika të përbashkëta me ato përvoja. Në fushën e albanologjisë, ky kontribut do të formësohet qartë duke përvijuar profilet e ligjëruesit të çështjeve të rëndësishme të qytetërimit dhe kulturës shqiptare në institucione universitare dhe shkencore me zë në Paris, të mësimdhënësit të shqipes dhe historisë së popullit shqiptar, të studiuesit të aspekteve të ndryshme të historisë, personaliteteve dhe veprave të panjohura të tyre, të përkthyesit të letërsisë artistike, shkencore e politike, të hulumtuesit dhe paraqitësit kompetent të dokumenteve arkivore, të hershme dhe të reja; po ashtu, edhe të mbrojtësit të vlerave kulturore të popullit shqiptar në foltore të ndryshme të Parisit e më gjerë, ku kultura shqiptare kishte çka të thoshte dhe ku zëri i K. Gytit tingëllonte bindshëm dhe i fortë. Mjediset ku ky zë do të dëgjohej shkonin nga salla e Parlamentit e Senatit francez, Ministrisë së Arsimit dhe Shkencës në Francë e deri në auditoret e Universitetit të Sorbonës a Institutit të Gjuhëve dhe Qytetërimeve Lindore. Ky kontribut i tij do të integrohet natyrshëm me atë traditë studiuesish francezë, duke u përshtatur, gjithsesi, me natyrën, kërkesat dhe nevojat bashkëkohore të një periudhe te re studimesh në fushën e albanologjisë.

Kristian Gyti lindi më 17 korrik 1931, në një familje inxhinierësh, në Paris, ku kreu me rezultate të shkëlqyera shkollën e mesme. Më 1951 doli i pari në konkursin e pranimit për studime universitare në instuticionin me zë Shkolla kombëtare e Kartave (École nationale des Chartes), të cilën e kreu me rezultate të jashtëzakonshme, sepse zuri vendin e dytë midis të diplomuarve. Në këtë shkollë përsosi njohjen e latinishtes e greqishtes së vjetër, si edhe mjeshtërinë e paleografit (1955).

I etur për dije dhe punëtor i palodhur, mësoi me të paharruarin Hanri Buasënin (Henri Boissin) gjuhën shqipe dhe maqedonase në Shkollën Kombëtare të Gjuhëve Lindore të Gjalla, ku u diplomua me notën shumë mirë si për shqipen (1966), ashtu edhe për maqedonishten (1968). 
Dashamiri dhe miku i shqiptarëve dhe i Shqipërisë Kristian Gyt ka mbrojtur edhe një doktoratë për qytetërimin shqiptar në Universitetin e Puatjesë (Poitiers) me vlerësimin më të lartë që ka Franca: Tepër i nderuar me urimet e jurisë.

Karrierën e vet K. Gyti e ka bërë në Francë si arkivist-paleograf, si kryearkivist i Departamentit të Uazës (Oise) (1955-1958); shef i shërbimit audio-vizual në Arkivat Kombëtare (1961-1966); drejtor i Arkivave të Senës (1966-1978); kryeruajtës i shërbimit teknik në Drejtorinë e Arkivave të Francës 19781984); drejtor i Qendrës spitalore të specializuar ndërdepartamentale të Klermont-dë-l’Uazë (1984-1989), etj. Karriera e tij është shumë më e pasur dhe e larmishme se kaq, ajo përbëhet edhe nga detyra e funksione të tjera; si ekspert pranë delagacionit francez në UNESKO (1976-1984); si ekspert i UNESKO-s për arkivat e Çadit, Kongos, Mauritanisë, Haitit, Qipros; si anëtar i Komitetit të mikrofilmit të Këshillit Ndërkombëtar të Arkivave (1975-1978); si nënkryetar i Qendrës Ndërkombëtare të Informacionit pêr burimet e historisë së Ballkanit (1976-1984); si anëtar i Komisionit epror të arkivave (1978-1984); si sekretar i Konferencës Ndërkombëtare të Tryezës së Rrumbullaktë të Arkivave (1966-1979), etj.

Dhe kjo nuk është veçse një pjesë vërtet e qënësishme, por gjithsesi vetëm një pjesë e karrierës e këtij njeriu që gjithë jetën ka bërë punë dhe vetëm punë të dobishme.

Për punë të palodhur dhe shumë të vlefshme, ai është nderuar me shumë tituj e dekorata nga më të lartat nga administrata franceze: Kalorës i Urdhërit Kombëtar të Legjionit të Nderit (Chevalier de l'Ordre national de la Légion d'honneur) (1983), Kalorës i Urdhërit Kombëtar të Meritës (Chevalier de l'Ordre national du Mérite) (1968), Oficer i Arteve dhe Letrave (Officier des Arts et des Lettres) (1978), etj.

Edhe si albanolog është treguar mjaft prodhimtar. Ka qenë i ngarkuar me ligjëratat për qytetërimin shqiptar (letërsi, histori, gjeografi), të cilat i krijoi vetë, në Institutin Kombëtar të Gjuhëve dhe Qytetërimeve Lindore të Parisit (1966-1992), i ngarkuar me mësimdhënien e gjuhës shqipe në po këtë Institut (1970-1992), drejtor i Departamentit të Europës Qendrore dhe Lindore të këtij Instituti (1971-1980) dhe zëvendës-drejtor i tij (1990-1992); meritë madhore e tij është krijimi i një strukture trevendëshe për mësimdhënien e gjuhës dhe të qytetërimit shqiptar në këtë Institut, strukturë që para tij mungonte. Po ashtu, ai zhvilloi ligjëratat për historinë dhe filologjinë shqiptare në Shkollën Praktike të Studimeve të Larta në Sorbonë. 


\section{Albanon}

\section{Revistë kulturore}

Pjesë të rëndësishme të interesimeve të tij si shkencëtar ai ka edhe studimin e botës shqiptare. Veprimtaria e tij si albanaolog është e larmishme dhe me ndihmesa të mira për studimin e gjuhës, historisë dhe qytetërimit shqiptar. Për ta përkapur më mirë këtë veprimtari po renditim ndihmesat e tij sipas tematikës dhe kohës.

Ai ka bërë punë të lavdërueshme për njohjen e Shqipërisë, të popullit dhe qytetërimit shqiptar në Francë dhe në botën frankofone, ka qenë ambasador dhe përçues i këtij qytetërimi në Francë dhe më gjerë, si dëshmojnë, ndër të tjera, edhe këto shkrime të tij nëpër enciklopedi dhe përmbledhje shkencore : "Notice sur l'histoire de l'Albanie» në Encyclopedia universalis, v. I, Paris, 1968, f. 551-554; «Notice sur Esad Mekuli» në Histoire des littératures, Paris, 1976; «La littérature albanaise» në Histoire littéraire de l'Europe médiane des origines à nos jours, Paris, 1998, f. 19-29; "Le Kossovo dans la littérature albanaise» në Annales de l'autre Islam, n 7 (2001), f. 37-41; «Notices sur la littérature albanaise des XIVème-XIXème siècle, la littérature populaire et orale» në Dictionnaire universel des littératures, Paris, 1994; «Pasco Wassa» në Dictionnaire universel des littératures, Paris, 1994, f. 83-84; 2946 dhe 3991. Këtyre u duhen shtuar edhe ligjëratat e videokonferencat për të drejtën zakonore shqiptare, sidomos për Kanunin e Lekë Dukagjinit.

Profesor Gyti i ka kushtuar vëmendje të veçantë mësimdhënies së gjuhës shqipe në Institutin Kombëtar të Gjuhëve dhe Qytetërimeve Lindore në Paris. Ai ka hartuar disa doracakë për këtë mësimdhënie, si «Les sources en langue albanaise de l'histoire de l'Albanie, des origines au début du XIXème siècle (fasc. 1). Sources littéraires», Paris, 1970, 34 f.; «Les sources en langue albanaise de l'histoire de l'Albanie, des origines au début du XIXème siècle (fasc. 2). Sources ethnographiques», Paris, 1970, 33 f., «Les sources de l'histoire de l'Albanie (fasc. 3). Littérature populaire», Paris, 1972, 33 f. dhe «Les sources ... de l'histoire de l'Albanie... (fasc. 4). Sources diplomatiques et juridiques».

Gjendjen e studimeve albanologjike dhe mësimdhënien e shqipes në Francë i ka parashtruar në shkrime e kumtesa të ndryshme, si, p.sh., "L'état présent des études albanologiques en France» në Akten des internationalen Kolloquiums ... zum Gedächtnis an Norbert Jokl, Innsbruck, 1977, f. 113-118 dhe «Mësimi i gjuhës shqipe në Francë dje dhe sot» në Gjuha jonë, n 1 / 4, Tiranë, 1995 f. 113-127. 
Përveç kontributeve shkencore si arkivist-paleograf i historisë së mesjetës franceze, me rreth 100 artikuj dhe disa libra të botuara për këtë fushë studimi, K. Gyti ka hartuar edhe për historinë e Shqipërisë një seri shkrimesh, si «Inventar i Korrespondencave të Konsujve të Francës në Durrës», 16991726, Gjurmime albanologjike, $\mathrm{n}^{\circ}$ 1-2, Prishtinë, 1970, p. 295-312; «Les structures administratives de l'Albanie pendant les premières années de son indépendance», Colloque Langues O', Paris, 1984, f. 75-85; "Notices sur l'histoire de l'Albanie, Ali pacha et Les îles ioniennes», Dictionnaire Napoléon, Paris, 1987, f. 59, 64-65 dhe 937-938; "Religions et identités culturelles en Europe centrale et orientale, l'exemple albanais», në Groupe de travaux sur l'Europe centrale et orientale. Bulletin d'information, $\mathrm{n}^{\circ} 2$, 1978, f. 38-41 dhe 50-58; «La commission internationale de contrôle et le statut organique de l'Albanie», Albanie, n 16, 1989, f. 26-32; "La vendetta dans le Kanun», Albanie utopie. Huis clos dans les Balkans, Paris, 1996, f. 62-67; "Organizimi administrativ, juridik dhe ushtarak i Shqipërisë, 1912-1914», Seminari XVIII ndërkombëtar për gjuhën, letërsinë dhe kulturën shqiptare, Tiranë, 1996, f. 47-54; "Une œuvre peu connue de Pasco Wasa, Esquisse historique sur le Monténégro», Seminari i katërt ndërkombëtar Shkodra në Shekuj, v. 1, Shkodër, 2002, f. 171-176; «Un document inédit sur les rapports de Pashko Vasa et de Preng Bib Doda", Akademia e Shkencave dhe e Arteve e Kosovës. Studime, 8-9, Prishtinë, 2002, f. 325-329; "Çështja e Lindjes», Buletini shkencor i Universitetit «Aleksandër Xhuvani»», Elbasan, 2004, n² 2, f. 207228; «Bosnja dhe Herzegovina vështuar prej Pashko Vasës (1863-1864)», Buletini shkencor i Universitetit "Aleksandër Xhuvani»», Elbasan, 2004, n 2, f. 97-106, etj.

Vëmendje të veçantë i ka kushtuar edhe studimit të shqipes, ndërtimit të saj gramatikor, sidomos në rrafshin filologjik, përqasës dhe krahasues: «Kontakte linguistike midis shqipes dhe maqedonishtes», Gjurmime albanologjike, ${ }^{\circ}$ III, 1973, f. 51-55; "Combien l'albanais a-t-il de cas?», Cahiers balkaniques, n 19, Paris, 1994, f. 207-216; « Një tekst shkodran i pabotuar i viteve 1850», Akademia e Shkencave dhe e Arteve e Kosovës. Studime, 4, 1997, Prishtinë, 1998, f. 147-158; "Edhe një herë për tekstin e pabotuar shkodran të viteve 1850", Akademia e Shkencave dhe e Arteve e Kosovës. Studime, 4, 1997, f. 339-341; "Vështrim përqasës midis sistemeve fonetike të gramatikës së Kostandin Kristoforidhit dhe asaj të Ogyst Dozonit», Përmbledhje me studime për Konstandin Kristoforidhin, Elbasan, 2002, f. 48-55; "Vështrim përqasës midis sistemeve [foljore] të gramatikës së Dozonit dhe asaj të Kristoforidhit, 


\section{Albanon}

Revistë kulturore

Eqrem Çabej dhe kultura shqiptare, Tiranë, 2004, f. 245-254; «Pashko Vasa dhe alfabeti», Akademia e Shkencave dhe e Arteve e Kosovës Studime, 12, Prishtinë, 2006, f. 61-65.

Megjithëse me funksione të larta në administratën franceze, ai ka gjetur kohën e duhur për të përkthyer disa prej veprave të njohura të letërsisë artistike, shkencore e politike shqiptare. Përkthimi i parë i botuar është La ville du Sud (Qyteti i jugut) i Ismail Kadaresë, Paris, 1985, 190 f., me parathënie të Robert Eskarpitit. Ka përkthyer në shqip poezitë e Pashko Vasës të hartuara në frëngjisht, Pashko Vasa, Vepra, t. I, Prishtinë, 1989, f. 315-326 dhe në frëngjisht poezi të Preç Zogajt, Poésie 93, n 46, Paris, 1993, f. 88-90. Ia ka dalë me sukses të përkthejë disa prej veprave nga më të vështirat për t’u përkthyer në gjuhë të huaj si Grandeur et décadence du camarade Zulo (Shkëlqimi dhe rënia e shokut Zylo) i Dritëro Agollit, Paris, 1990, 285 f.; La mort me vient de ces yeux-là (Vdekja më vjen prej syve të tillë) i Rexhep Qoses, Paris, 1994, 321 f. me parathënie të Ismail Kadaresë dhe Kanun de Lekë Dukagjini (Kanuni i Lekë Dukagjinit), Pejë, 2001, 298 f. Për përkthimin e romanit Shkëlqimi dhe rënia e shokut Zylo është shkuar deri aty sa të thuhet se nuk është përkthim, por i shkruar në frëngjisht, dhe s'kishte sesi të ishte ndryshe, se e ka zgjatur përkthimin për vite të tëra, e ka limuar, i ka thënë gjërat ashtu si i thonë vetë nëpunësit francezë. Përkthimi i Kanunit të Lekë Dukagjinit, që i mori rreth 15 vite pune, është i vetmi deri më sot në frëngjisht. Ai është jo vetëm më i ploti, por edhe më i sakti ndër të gjitha përkthimet e bëra në gjuhë të tjera deri më sot, çka dëshmon për njohje të thellë të ligjit të maleve shqiptare. Një përkthim i tillë ndihmon për njohje më të mirë të vetëqeverisjes tradicionale shqiptare, por që, si model i vërtetë përkthimi, mund të ndihmojë njëherazi për përkthimin e Kanunit të Lekë Dukagjinit në gjuhë të tjera.

Ndër përkthimet me karakter më të përgjithshëm, janë edhe «Deklarata e përgjithshme mbi të drejtat e njeriut», (nga frëngjishtja në shqip), Republika, $\mathrm{n}^{\circ}$ 1/2, 1994, f. 28-29 dhe La question albanaise (Çështja shqiptare) e Rexhep Qoses, Paris, 1995, 326 f. Ai ka të përkthyera, por të pabotuara, edhe vepra të tjera, si Lulja e kujtimit e Foqion Postolit, etj. Me përkthimet e veta nga shqipja në frëngjisht ka ndihmuar kolegët dhe miqtë e vet shqiptarë, si, p.sh., shkrimin e gjatë të Andromaqi Gjergjit «Kultura popullore shqiptare», për përmbledhjen Peuples et civilisations européennes, l'Encyclopédie de la Pléiade, etj., etj. Ai ndodhej në punë e sipër për përgatitjen e materialeve për 
një histori të Skënderbeut në frëngjisht dhe një tjetër për të drejtën zakonore shqiptare. Njeriu që nuk dinte veçse të punonte, ishte duke bashkëpunuar gjithashtu për një fjalor shqip-frëngjisht të tipit të mesëm.

Letërsia shqiptare e ka joshur gjithmonë mikun e nderuar të shqiptarëve, ai është marrë gjatë me të dhe i ka kushtuar një seri shkrimesh, ndër të cilat mund të përmenden: "Poezitë e papërfillura të Pashko Vasës», Gjurmime albanologjike, seria e shkencave filologjike, $\mathrm{n}^{\circ}$ XVI, Prishtinë, 1986, f. 169-182; «Mbi gjendjen ekonomike të familjes së Pashko Vasës», Gjurmime albanologjike, seria e shkencave historike, $\mathrm{n}^{\circ}$ XVII, Prishtinë, 1987, f. 171-176; "Një ndodhi e panjohur nga jeta e Pashko Vasës», Studime filologjike, Tiranë, 1988, $\mathrm{n}^{\circ}$ 2, f. 197-199; "[Pashko Vasa], Biografia me bibliografi ", Pashko Vasa. Vepra, IV, Prishtinë, 1989, f. 233-238; "Conscience nationale et conscience européenne dans l'oeuvre d'Ismaïl Kadare», Colloques langues O'. Convergences européennes, Paris, 1993, f. 247-259; "Dorëshkrimet e vjershës $O$ moj shqypni të Pashko Vasës», Studime filologjike, Tiranë, 1993, n 1-4, f. 137-140; «Pashko Vasa et son ouvre», Akademia e Shkencave dhe Arteve e Kosovës. Studime, 10, Prishtinë, 2004, f. 29-32, etj.

Përveç librave për historinë mesjetare të Francës, ka botuar edhe dy libra të karakterit albanologik: Parlons albanais, Paris, 1999, 485 f., ribotuar disa herë, dhe Pashko Vasa, Prishtinë, 2008, 275 f.

I pari, fryt i një bashkëpunimi me kolegë, është doracak me njoftime historike, gjeografike, etnografike, letrare, gjuhësore dhe me disa tekste bashkëbisedimesh nga më të nevojshmet, si edhe me dy fjalortha shqipfrëngjisht dhe frëngjisht-shqip. Ky doracak mbetet deri tani më i ploti në llojin e vet.

I dyti, është studimi më i plotë monografik deri më sot për rilindasin e madh, që kaq shumë e ka joshur K. Gytin dhe për të cilin ai ka punuar vite e vite të tëra. Në këtë libër, fryt i një pune monografike kërkimore disadhjetëvjeçare, lexuesi gjen materiale dhe fakte të reja të njohura pak ose aspak për rilindasin tonë të ndritur, por edhe saktësinë dhe thellësinë e analizës shkencore të autorit.Vitet nuk e patën ndalur profesor Gytin të jetë i pranishëm edhe në mjediset universitare shqiptare, me kumtesa, cikle ligjëratash dhe shkrime në periodikët shkencorë të universiteteve shqiptare. Ai ka qenë i pranishëm në auditoret, foltoret dhe buletinet shkencore të Universitetit të Tiranës, të 


\section{Albanon}

\section{Revistë kulturore}

Universitetit të Elbasanit 'A. Xhuvani', të Universitetit të Shkodrës 'Luigj Gurakuqi', të atij të Gjirokastrës 'E. Çabej’ etj.

Magister dixit (Mjeshtri e tha fjalën e tij) - thekson një thënie latine. Në respekt të kësaj fjale, institucione të ndryshme universitare dhe shkencore shqiptare e kanë nderuar atë me tituj të lartë shkencorë dhe akademikë, si Anëtar i jashtëm i Akademisë së Shkencave dhe Arteve të Kosovës (1996), Profesor i jashtëzakonshëm i Universitetit «Aleksandër Xhuvani» të Elbasanit (1998), Doktor Honoris Causa i Universitetit të Tiranës (2000).

Mjeshtri e tha fjalën e tij - por në fakt mjeshtri tha shumęçka jo vetëm përmes fjalës, por edhe veprimit që nxitet nga shpirti. Ecce Homo (Ja njeriu) - do të mund të përsëritnim duke iu referuar një latinizmi të huazuar më tej edhe nga Niçja. Me një akt domethënës bamirësie profesor K. Gyti i dhuroi Bibliotekës së Universitetit të Elbasanit bibliotekën e vet albanologjike e balkanologjike, fondi i së cilës arrin në rreth 5 mijë ekzemplarë, që përfshijnë rreth 3500 tituj; tituj që do t'i bënin nder çdo biblioteke universitare e akademike. Në të ka vlera, libra të rrallë e botime të vjetra si Historia e Skënderbeut e Lavardënit, Fjalori i F. Bardhit, Gramatika e gjuhës shqipe e Ogyst Dozonit etj., sidomos libra të botuar në shekullin XX, tashmë të rrallë. Me interes është fakti se ka, në seri të plota, revistat dhe përmbledhjet albanologjike të botuara në Shqipëri, Kosovë, diasporë e gjetiu.

Dhurimi i një biblioteke të tërë sjell në mjedisin ku dhurohet jo vetëm dijeni, kulturë, informacion, por, njëkohësisht me to, edhe praninë e gjithëkohshme pranë atij institucioni të modelit të dijetarit që e ka krijuar në vite atë pasuri, si shenjë të përkushtimit mendor ndaj një gjuhe, kulture dhe qytetërimi; sjell praninë e modelit të studiuesit që ka qëmtuar me kujdes dhe dashuri vlerat e atij qytetërimi, duke u lënë brezave të studiuesve dhe studentëve frymën e dijes. Ishte ky model, i ngjizur në vlera të spikatura intelektuale dhe shpirtërore të cilin Këshilli Bashkiak i qytetit të Elbasanit kërkoi ta nderojë duke i akorduar profesor K. Gytit titullin "Qytetar nderi” (2012).

Ashtu si pasionet e mëdha përftojnë vlera që nuk kufizohen në kohë, po ashtu edhe respekti ynë ndaj përftuesve të atyre vlerave është po ashtu i pakohë, mbetet gjithnjë $i$ pranishëm ndaj tyre: ad vitam aeternam / në përhershmëri. 